NBER WORKING PAPER SERIES

\title{
THE ROLE OF BEQUESTS IN SHAPING WEALTH INEQUALITY: EVIDENCE FROM DANISH WEALTH RECORDS
}

\author{
Simon H. Boserup \\ Wojciech Kopczuk \\ Claus T. Kreiner \\ Working Paper 21896 \\ http://www.nber.org/papers/w21896 \\ NATIONAL BUREAU OF ECONOMIC RESEARCH \\ 1050 Massachusetts Avenue \\ Cambridge, MA 02138 \\ January 2016
}

We thank our discussant at the AEA 2016 meeting Kathleen McGarry as well as numerous seminar and workshop participants for comments and discussion. Financial support from the Economic Policy Research Network (EPRN) and the Danish Council for Independent Research (DFF - 1329-00046) is gratefully acknowledged. The views expressed herein are those of the authors and do not necessarily reflect the views of the National Bureau of Economic Research.

NBER working papers are circulated for discussion and comment purposes. They have not been peerreviewed or been subject to the review by the NBER Board of Directors that accompanies official NBER publications.

(C) 2016 by Simon H. Boserup, Wojciech Kopczuk, and Claus T. Kreiner. All rights reserved. Short sections of text, not to exceed two paragraphs, may be quoted without explicit permission provided that full credit, including $(\mathrm{C}$ notice, is given to the source. 
The Role of Bequests in Shaping Wealth Inequality: Evidence from Danish Wealth Records Simon H. Boserup, Wojciech Kopczuk, and Claus T. Kreiner NBER Working Paper No. 21896

January 2016

JEL No. D31,E21,J62

\begin{abstract}
Using Danish administrative data, we estimate the impact of bequests on the level and inequality of wealth. We employ an event study design where we follow the distribution of wealth over time of people who are 45-50 years old, and divide them into treatment group and control group depending on whether a parent dies or not. Bequests account for 26 percent of the average post-bequest wealth 1-3 years after parental death and significantly affect wealth throughout the distribution. We find that bequests increase measures of absolute wealth inequality (variance), but reduce relative inequality (top wealth shares). Following the receipt of bequests, variance of the distribution censored at the top/bottom $1 \%$ increases by 33 percent, but the top $1 \%$ share declines by 6 percentage points from an initial level of 31 percent and the top $10 \%$ share declines by 10 percentage points from a base of around 81 percent.
\end{abstract}

Simon H. Boserup

Department of Economics

University of Copenhagen

$\varnothing$ ster Farimagsgade 5

Building 26

DK-1353 Copenhagen K

Denmark

shb@econ.ku.dk

Wojciech Kopczuk

Columbia University

420 West 118th Street, Rm. 1022 IAB

MC 3323

New York, NY 10027

and NBER

wk2110@columbia.edu
Claus T. Kreiner

Department of Economics

University of Copenhagen

Øster Farimagsgade 5

Building 26

DK-1353 Copenhagen K

Denmark

claus.thustrup.kreiner@econ.ku.dk 
Intergenerational transfers are one of the main channels through which economic outcomes of subsequent generations are linked. Influential literature that originated in the 1980s (Kotlikoff and Summers, 1981; Modigliani, 1988) and is summarized in Davies and Shorrocks (2000) focused on the contribution of bequests to aggregate wealth (or capital stock). Recent work of Piketty (2011, 2014) brought back to the forefront the question of the role of bequests in shaping inequality.

In this paper, we use Danish administrative records that allow us to observe wealth of parents and children and employ an event study design to characterize how the flow of bequests following death of a parent influences the level and distribution of wealth among children age $45-50 .{ }^{1}$ In our companion papers (Boserup, Kopczuk and Kreiner, 2015a,b) we study more generally the strength of intergenerational wealth correlation, accounting for the role of human capital transmissions, inter-vivos gifts, and bequests.

We find that bequests increase average wealth of recipients by about 36 percent implying that bequests account for 26 percent of average post-bequest wealth.

It is unclear a priori whether bequests are dis-equalizing or equalizing. Bequests may disproportionately benefit poor individuals and reduce inequality or they may primarily increase wealth of people who are already wealthy and enhance inequality.

We find that bequests increase the variance of wealth (censored at 1st and 99th percentiles) by 33 percent and that this level is the same three years after parental death. The percentiles in the wealth distribution increase, and the higher the percentile the larger the absolute increase. Thus, bequests stretch the distribution to the right. This large increase in absolute inequality is not reflected in relative inequality measures such as top wealth shares. For example, the top $1 \%$ wealth share decreases by 6 percentage points from a pre-bequest level of 31 percent. Thus, whether bequests are dis-equalizing or equalizing depends on whether inequality is measured in absolute terms or relative terms.

\section{Institutional background}

Denmark has forced heir-ship rules implying that $1 / 4$ of the inheritance has to go to the close family of the deceased, with an equal split between the spouse and their children. For close family

\footnotetext{
${ }^{1}$ In a contemporaneous paper, Elinder, Erixson and Waldenström (2015) pursue a related analysis using Swedish administrative data.
} 
(other) recipients, bequest is taxed at a flat rate of 15 (36.25) percent above the basic allowance, which in 2015 equals DKK 272,900 (corresponding to around USD 40,000). A spouse may retain undivided possession of the estate, implying that wealth is not transferred to the next generation before death of both parents. Gifts above a small yearly allowance are taxed at the same rates as bequests, and wealth is untaxed in Denmark.

\section{Data and empirical approach}

Our empirical analysis is based on population and wealth registers from Statistics Denmark. Population registers enable us to link individuals born in 1960 and onwards to their parents. Wealth registers contain the aggregate value of asset holdings and liabilities of each individual in the population at the end of the year. This information is based mainly on third-party reports from financial institutions to the Danish tax agency about the value of deposits, bonds, listed stocks, and all types of debt carrying an interest rate. In addition, the cash value of property is assessed by the tax agency. $^{2}$ The data does not include information on pension wealth. We observe wealth of both parents and children from 2003 to 2013 or until death. More details about the wealth registers may be found in Boserup, Kopczuk and Kreiner (2015b).

A limitation of our data is that we do not observe inheritances directly. However, we do observe wealth of a parent in years preceding death, so that we effectively observe potential bequests. We also observe changes in children's wealth that reflect receipt of the actual bequest. Another strength of the data is that the analysis of the consequences for the wealth of the next generation accounts not only for bequests, but also for other wealth transfers taking place shortly before death and expenditures of children related to parental deaths.

The longitudinal nature of our data and large sample size allow us to implement a simple and transparent approach, where we compare the distribution of wealth among those whose parent dies in 2010 (treatment group) to those whose parent remains alive (control group) in the years before and after parental death. We present our results graphically and illustrate that the parallel trends assumption is consistent with the data. We focus on children who are between 45 and 50 years old

\footnotetext{
${ }^{2}$ It is well-known that assessed housing values for tax purposes are often lower than market values. We follow Leth-Petersen (2010) and scale up registered housing values by the average ratio of actual house prices to assessed values for the houses sold in the period 2003-2013, which gives a scaling factor of 1.16.
} 
in 2010, so that parents are observed in the data; and restrict attention to those with a single living biological parent in 2009, so that parental death corresponds to the flow of bequests to children (rather than to a surviving spouse). ${ }^{3}$ This yields a sample of 6,252 individuals in the treatment group and 148,166 individuals in the control group.

It is well-known that time of death is related to socio-economic status implying that wealth of parents (and children) is lower in the treatment group than in the control group. To facilitate comparison of children receiving bequest with those not receiving bequest, we order parents by average wealth in 2003-2009 and reweight the control group to match the percentile distribution of the treatment group for each child cohort. In the electronic appendix, we display average parental wealth in the treatment group compared to the control group before and after reweighting, as well as the difference in average wealth of the children in the two groups before reweighting, which may be compared to the weighted version displayed in Figure 1.

\section{Results}

Figure 1 shows the average wealth of children in the treatment group relative to the (weighted) control group, with the corresponding 95 percent confidence interval. In years preceding death of the parent, there is almost no difference between the two groups (note that matching is on parental wealth rather than child wealth), supporting the parallel trends assumption. After death of the parent, child wealth increases markedly relative to the level of wealth observed in the control group. Due to the timing of inheritance, this effect is partially visible in the year of death and is fully phased in the year after death of the parent. The increase in the year before death of the parent, although not significant, may reflect pre-death wealth transfers in order to avoid paying the bequest tax (Kopczuk, 2007). In the second and third year after parental death, the effect weakens slightly but this is statistically insignificant.

In Table 1, we report the difference-in-difference estimate of the change in the average wealth level of the treatment group from $t=-2$ to $t=1$ relative to the (weighted) control group, which is equal to DKK 127,130. Comparing this estimated change to the average wealth level of the control

\footnotetext{
${ }^{3}$ The parent may have remarried. In this case, spouse and children each inherit half of the estate of the deceased when the parent dies unless stated otherwise in a will. The spouse cannot retain undivided possession of the estate unless children give their consent.
} 


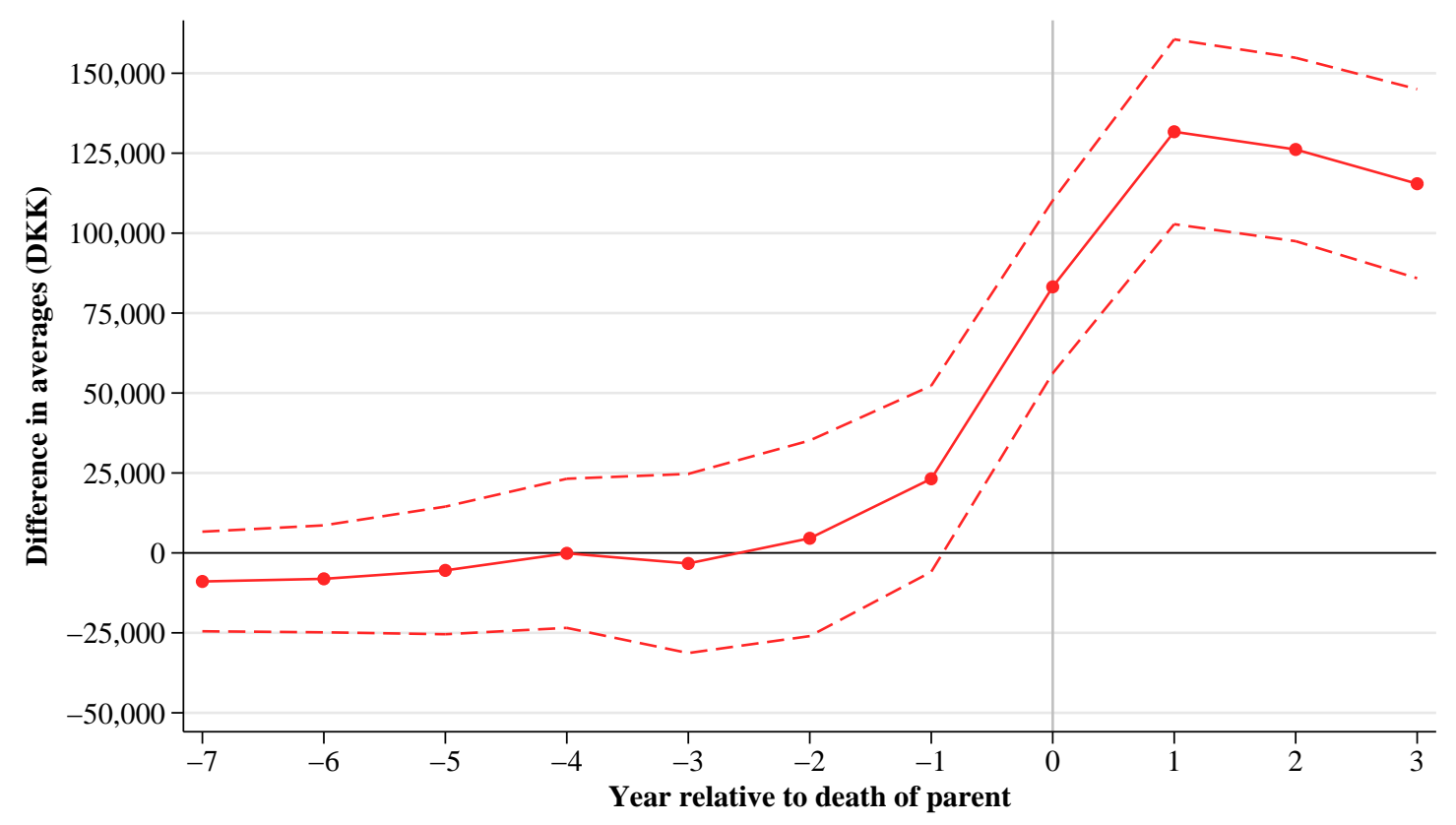

Figure 1. Effect of Death of the Parent on Wealth of the Child

Note: The graph shows the difference in the average wealth of children in treatment and control groups; control group reweighted to match, for each child cohort, the percentile distribution of parental wealth in the treatment group. Percentile ranks of parents are calculated within each child cohort based on average wealth seven years before death. Amounts in 2010 DKK, $\$ 1=$ DKK5.6. Distributions censored at $1^{\text {st }}$ and $99^{\text {th }}$ percentiles. Dashed lines are 95 percent confidence intervals based on standard errors clustered by parents (who may have more than one child).

Table 1. Effect of Bequests on the Wealth Distribution

\begin{tabular}{|c|c|c|c|c|}
\hline & $\begin{array}{c}\text { Control group } \\
\text { wealth level } 2011\end{array}$ & $\begin{array}{l}\text { Treatment - control } \\
\text { DiD } 2011 \text { vs. } 2008\end{array}$ & \multicolumn{2}{|c|}{$95 \%$ confidence interval } \\
\hline Average & 352,124 & 127,130 & 111,960 & 172,309 \\
\hline \multicolumn{5}{|l|}{ Percentiles } \\
\hline 10 & $-339,739$ & 26,926 & 11,230 & 48,557 \\
\hline 25 & $-101,304$ & 24,592 & 16,864 & 29,472 \\
\hline 50 & 81,987 & 75,175 & 50,920 & 96,317 \\
\hline 75 & 568,347 & 155,534 & 136,010 & 197,151 \\
\hline 90 & $1,282,101$ & 330,872 & 275,594 & 411,299 \\
\hline 95 & $2,009,479$ & 397,805 & 259,975 & 549,765 \\
\hline 99 & $5,284,129$ & 875,789 & 614,781 & $1,902,831$ \\
\hline
\end{tabular}

Note: Average and percentiles of the control group distribution (column 1) and the difference-in-difference estimates of the impact of bequests on the average and percentiles using 2008 and 2011 comparison (column 2). 95 percent confidence intervals (columns 3-4) based on 1,000 bootstrap replications clustered by parents. Distributions censored at $1^{\text {st }}$ and $99^{\text {th }}$ percentiles. All amounts in 2010 DKK. $\$ 1=$ DKK 5.6. 
group at $t=1$, we find that bequests on average increase wealth by 36 percent. Equivalently, bequests account for 26 percent $(=0.36 / 1.36)$ of overall wealth of the treatment group, which is closer to the estimate of Modigliani (1988) than the one by Kotlikoff and Summers (1981). ${ }^{4}$

In the rest of the paper, we analyze distributional consequences of bequests. Figure 2, top panel, shows the impact on the variance of wealth. Distributions are censored at percentiles 1 and 99 for each group in each year to abstract from very low and very high wealth; we analyze the development of the top $1 \%$ separately in what follows. The graph shows the difference between the variances of the treatment and control group measured relative to the variance of the control group. There is little difference between the groups before parental death. Following death of a parent, the variance increases by 33 percent relative to the control group. Under the parallel trends assumption, this is the causal estimate of the effect of receipt of inheritance on the variance of the wealth distribution outside of the top and bottom $1 \%$.

The bottom panel of Figure 2 shows the impact of bequests on the 75th percentile of the wealth distribution. It is computed by taking the difference between the 75 th percentiles of the treatment group and of the (weighted) control group. In line with the parallel trend assumption, the curve is flat until the year before death of a parent, with almost no difference between treatment and control groups, and then jumps up to a new level of around DKK 150,000. Similar graphs for other percentiles reveal qualitatively the same type of development, but quantitatively we observe that the increase is larger the higher the percentile. This is summarized in Table 1, which also shows the wealth level of each percentile without including bequest, calculated from the control group. All the percentiles increase, but the amounts are small in the lower part of the distribution and increase as we move up in the distribution, implying that the distribution widens everywhere.

Much of recent work on inequality has focused on relative rather than absolute inequality. While bequests increase variance, they might still equalize relative distribution. For example, a proportional increase in wealth levels of everybody increases variance without affecting top wealth shares and the Gini coefficient. In that respect, notice from Table 1 that the median wealth level increases by more than 90 percent, while the wealth level of the $99^{\text {th }}$ percentile only increases by 17 percent. Thus, although the median increases by a small amount compared to the $99^{\text {th }}$ percentile,

\footnotetext{
${ }^{4}$ These results and Figure 1 are based on wealth distributions censored at the $1^{\text {st }}$ and $99^{\text {th }}$ percentiles. Without censoring, bequests on average increase wealth by 34 percent and bequests account for 25 percent of overall wealth of the treatment group.
} 

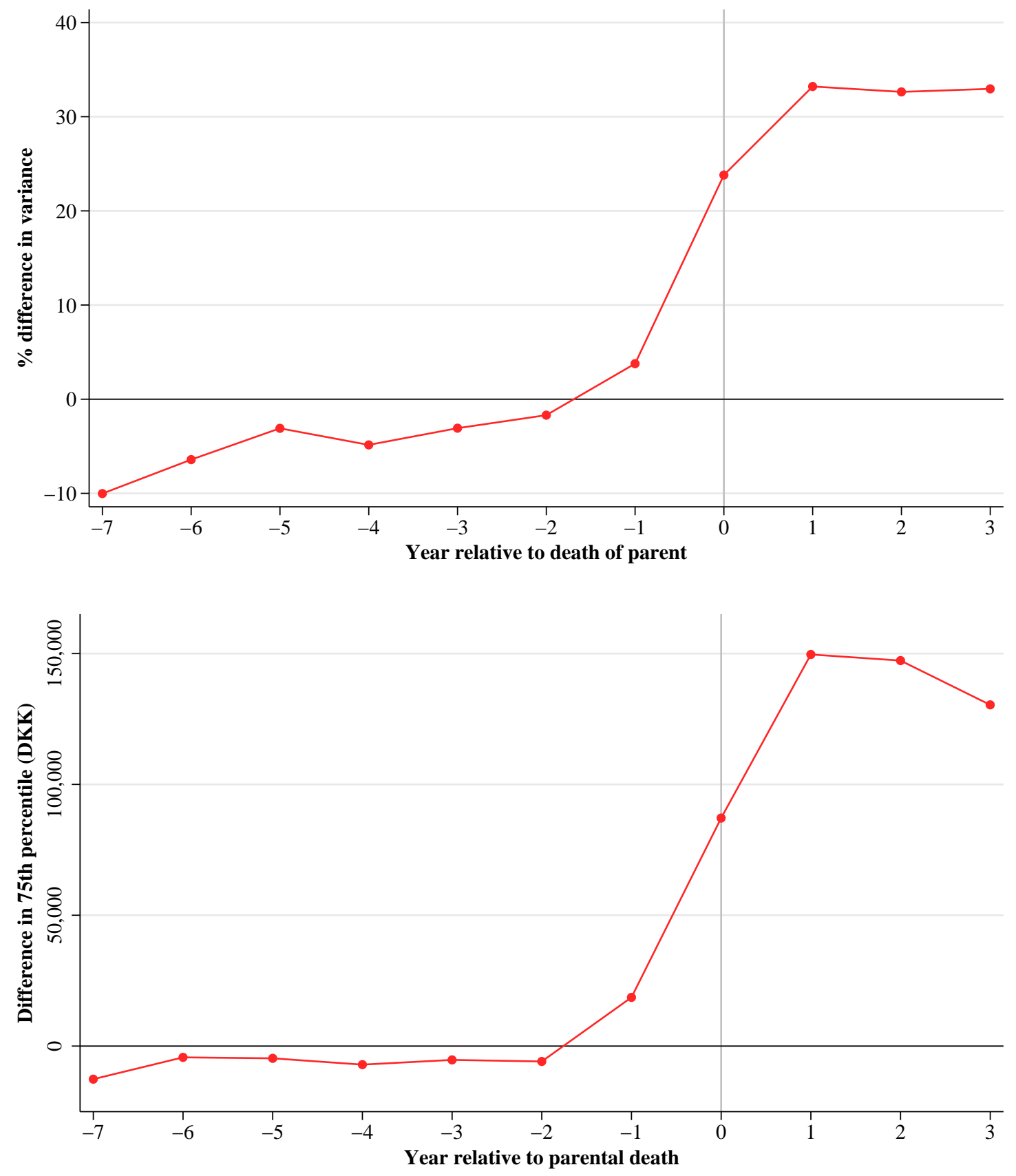

Figure 2. Effect of Bequests on the Variance and the 75th Percentile of the Wealth Distribution

Note: Percentage difference in variance of treatment group relative to control group (top panel), and difference between treatment group and control group in the value of the $75^{\text {th }}$ percentile (bottom panel). Variance based on the distributions censored at the $1^{\text {st }}$ and $99^{\text {th }}$ percentiles. Weighting as in Figure $1 . \$ 1=$ DKK5.6 in 2010 . 


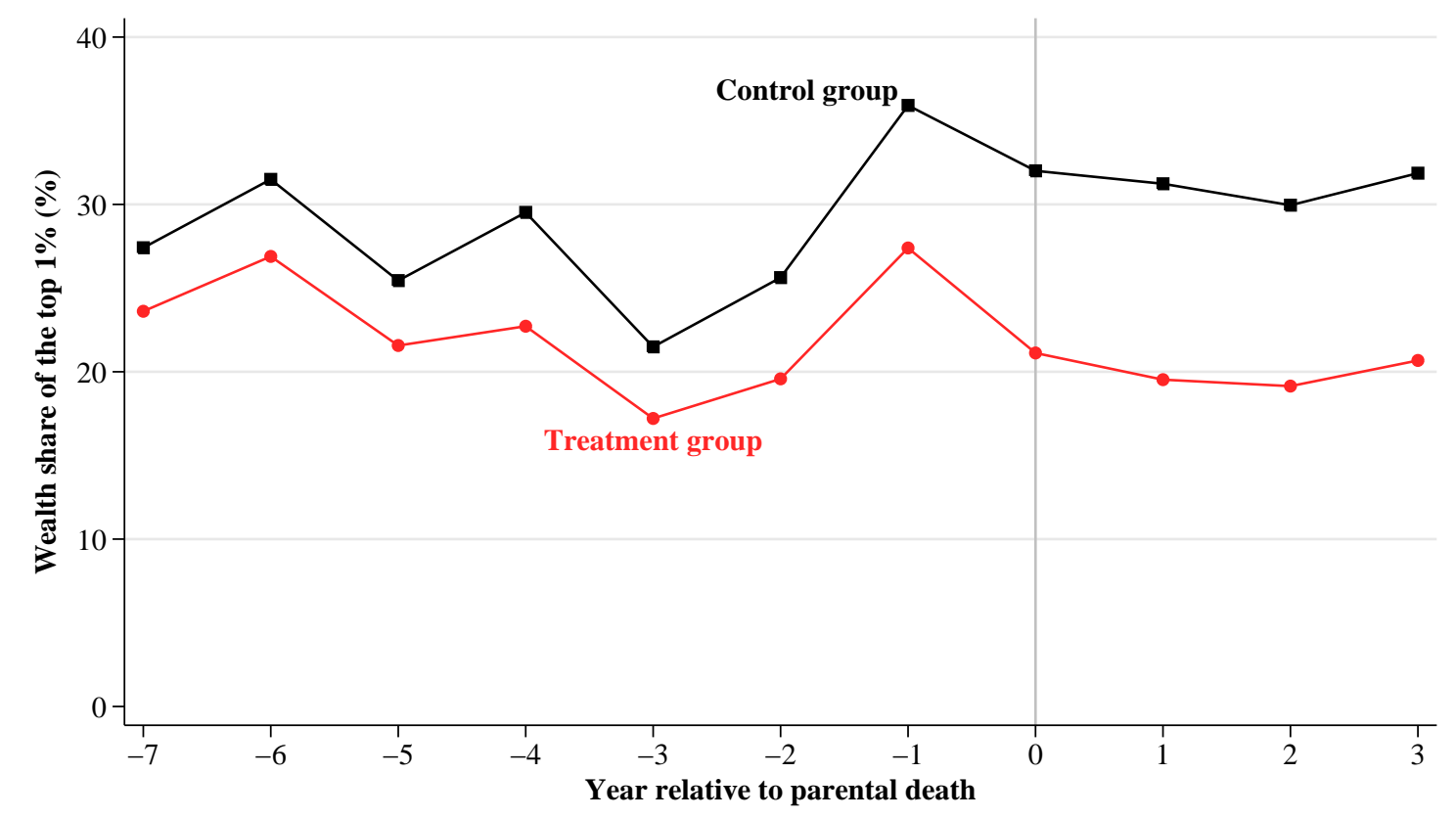

Figure 3. Effect of Bequests on Top 1\% Share of Wealth

Note: Top $1 \%$ share in the treatment and control groups. Weighting as in Figure 1.

the increase is large relative to the low baseline level of wealth holdings.

Due to negative wealth at the lower part of the distribution and its high concentration, the Gini coefficient is not particularly informative. In the following, we focus on the impact of bequests on wealth shares.

Figure 3 displays the development over time in the share of wealth owned by the top $1 \%$ richest within the treatment group and within the control group, respectively. Before death of a parent, the top $1 \%$ wealth share of the treatment group is a little below the level of the control group, but the two curves are reasonably parallel and co-vary around a share of 20-30 percent. Afterwards, the gap between the two curves clearly increases and remains stable in the three years after death of the parent. This implies that bequests decrease the wealth share of the top $1 \%$ group. We observe the same qualitative pattern if looking at the top $5 \%$ group or the top $10 \%$ group.

The results are summarized in Table 2. The first column shows wealth shares without bequests obtained from the control group. We obtain a top 1\% wealth share of 31 percent and a top $10 \%$ share of 81 percent. Our main results in column 2 show that bequests reduce the top shares and also decrease the wealth shares of the intermediate groups (top 5-1\% and top 10-5\%). For example, 
Table 2. Effects of Bequests on Wealth Shares

\begin{tabular}{lcccc}
\hline \hline $\begin{array}{l}\text { Wealth } \\
\text { group }\end{array}$ & $\begin{array}{c}\text { Control group } \\
\text { wealth share 2011 } \\
\text { (percent) }\end{array}$ & $\begin{array}{c}\text { Treatment - control } \\
\text { DiD 2011 vs. 2008 } \\
\text { (percentage points) }\end{array}$ & 95\% confidence interval \\
\hline Top 1\% & 31.2 & -5.7 & -6.9 & -3.9 \\
Top 5\% & 61.4 & -8.4 & -10.1 & -6.9 \\
Top 10\% & 81.4 & -9.9 & -12.3 & -8.7 \\
Top 5-1\% & 30.1 & -2.8 & -3.9 & -1.3 \\
Top 10-5\% & 20.0 & -1.5 & -2.8 & -0.6 \\
\hline
\end{tabular}

Note: Wealth shares in the control group distribution (column 1) and difference-in-difference estimates of the impact of bequests on top wealth shares using 2008 and 2011 comparison (column 2). 95 percent confidence intervals (columns 3-4) based on 1,000 bootstrap replications clustered by parents.

the top $10 \%$ share decreases by 10 percentage points from an original level of around 81 percent (and, correspondingly the share of wealth of the bottom $90 \%$ increases by the same amount).

The estimated wealth shares are comparable to the U.S. ones (see Kopczuk, 2015, for a discussion). The top $1 \%$ share in the U.S. is estimated to be between 35 and 40 percent depending on the method and the top 10\% wealth share is around 80 percent. These U.S. estimates are a mix of before- and after-bequests distributions. Our results suggest that the pre-bequest distribution corresponds to higher wealth shares, while the after-bequest distribution corresponds to lower wealth shares than these estimates indicate.

\section{Conclusions}

Comparison of wealth holdings of children whose parents die to those whose parents do not allows for identifying the effect of bequests on the distribution of wealth of the next generation. Our results show that bequests have on impact a large effect throughout the distribution and increase the overall variance of wealth by about 33 percent. This large increase in absolute inequality does not carry over to relative inequality measures such as top wealth shares. On the contrary, top wealth shares decrease. For example, the top $1 \%$ wealth share decreases by 6 percentage points from the without-bequest level of 31 percent.

Our estimates are by their nature short term effects. We study the effect only three years out and, by construction, over time parents in the control group are beginning to die as well. In the 
electronic appendix, we follow the same cohorts but look instead at deaths in 2007, where children are 42-47 years old, and compare the individuals to a control group where the parent is alive in 2013. ${ }^{5}$ The impact on average wealth is DKK 125,000 at $t=1$ as in Figure 1 and more than 60 percent of this effect is still present six years after. The impact on the variance in Figure 2 and on the top $1 \%$ wealth share in Figure 3 becomes slightly larger for this sample and these effects are almost unchanged up to six years after death of the parent.

Bequests are only one of the channels behind intergenerational transmission of wealth. Our companion papers (Boserup, Kopczuk and Kreiner, 2015a,b) study the role of inter-vivos transfers received in childhood and, more generally, the intergenerational correlation of wealth over the life-cycle, which depends in part on wealth transfers, but also on intergenerational dependency in human capital formation and savings patterns.

\section{References}

Boserup, Simon Halphen, Wojciech Kopczuk, and Claus Thustrup Kreiner. 2015a. "Born with a silver spoon: Danish evidence on intergenerational wealth formation from cradle to adulthood." University of Copenhagen and Columbia University, mimeo.

Boserup, Simon Halphen, Wojciech Kopczuk, and Claus Thustrup Kreiner. 2015b. "Intergenerational wealth formation over the life-cycle." University of Copenhagen and Columbia University, mimeo.

Davies, James B., and Anthony F. Shorrocks. 2000. "The Distribution of Wealth.” In Handbook of Income Distribution., ed. Anthony B. Atkinson and François Bourguignon. Amsterdam; New York:Elsevier.

Elinder, Mikael, Oscar Erixson, and Daniel Waldenström. 2015. "Inheritance and wealth inequality: Evidence from population registers." Uppsala Center for Fiscal Studies Working Paper 3.

\footnotetext{
${ }^{5}$ The disadvantage of this strategy is the much larger difference in timing of parental deaths, which makes treatment and control groups less similar.
} 
Kopczuk, Wojciech. 2007. "Bequest and Tax Planning: Evidence from Estate Tax Returns." Quarterly Journal of Economics, 122(4): 1801-1854.

Kopczuk, Wojciech. 2015. "What Do We Know About the Evolution of Top Wealth Shares in the United States?" Journal of Economic Perspectives, 29(1): 47-66.

Kotlikoff, Laurence J., and Lawrence H. Summers. 1981. "The Role of Intergenerational Transfers in Aggregate Capital Accumulation." Journal of Political Economy, 89(4): 706-732.

Leth-Petersen, Søren. 2010. "Intertemporal consumption and credit constraints: Does consumption respond to an exogenous shock to credit?" American Economic Review, 100(3): 1080-1103.

Modigliani, Franco. 1988. "The Role of Intergenerational Transfers and Life Cycle Saving in the Accumulation of Wealth." Journal of Economic Perspectives, 2(2): 15-40.

Piketty, Thomas. 2011. "On the Long-Run Evolution of Inheritance: France 1820-2050." Quarterly Journal of Economics, 126(3): 1071-1131.

Piketty, Thomas. 2014. Capital in the Twenty-First Century. Cambridge:Harvard University Press. 


\section{APPENDIX}

\section{A Matching Quality of Reweighting Approach}

Figure A.4 below shows average parental wealth in the treatment group and the control group before reweighting (top panel) and after reweighting (bottom panel). We reweight the control group to match, for each child cohort, the percentile distribution of parental wealth in the treatment group. Percentile ranks of the parents are calculated within each child cohort, based on average parental wealth in the years 2003-2009, where parental wealth is the sum of wealth of the living biological parents in each year. Without reweighting the two graphs are reasonably parallel, but parental wealth is significantly lower in the treatment group. This is as expected as it is well-known that timing of death is correlated with socio-economic status. After reweighting the control group, the two curves are nearly identical.

Because of the correlation between parental wealth and time of parental death and intergenerational dependency in wealth, it is natural to expect that child wealth of the treatment group on average is below the level of the control group. Figure A.5 shows the difference between the average wealth of the treatment group and the control group without reweighting of the control group. The graph is very similar to Figure 1 in the main text with the exception, as expected, of a permanently lower level of wealth of the treatment group relative to the control group. 

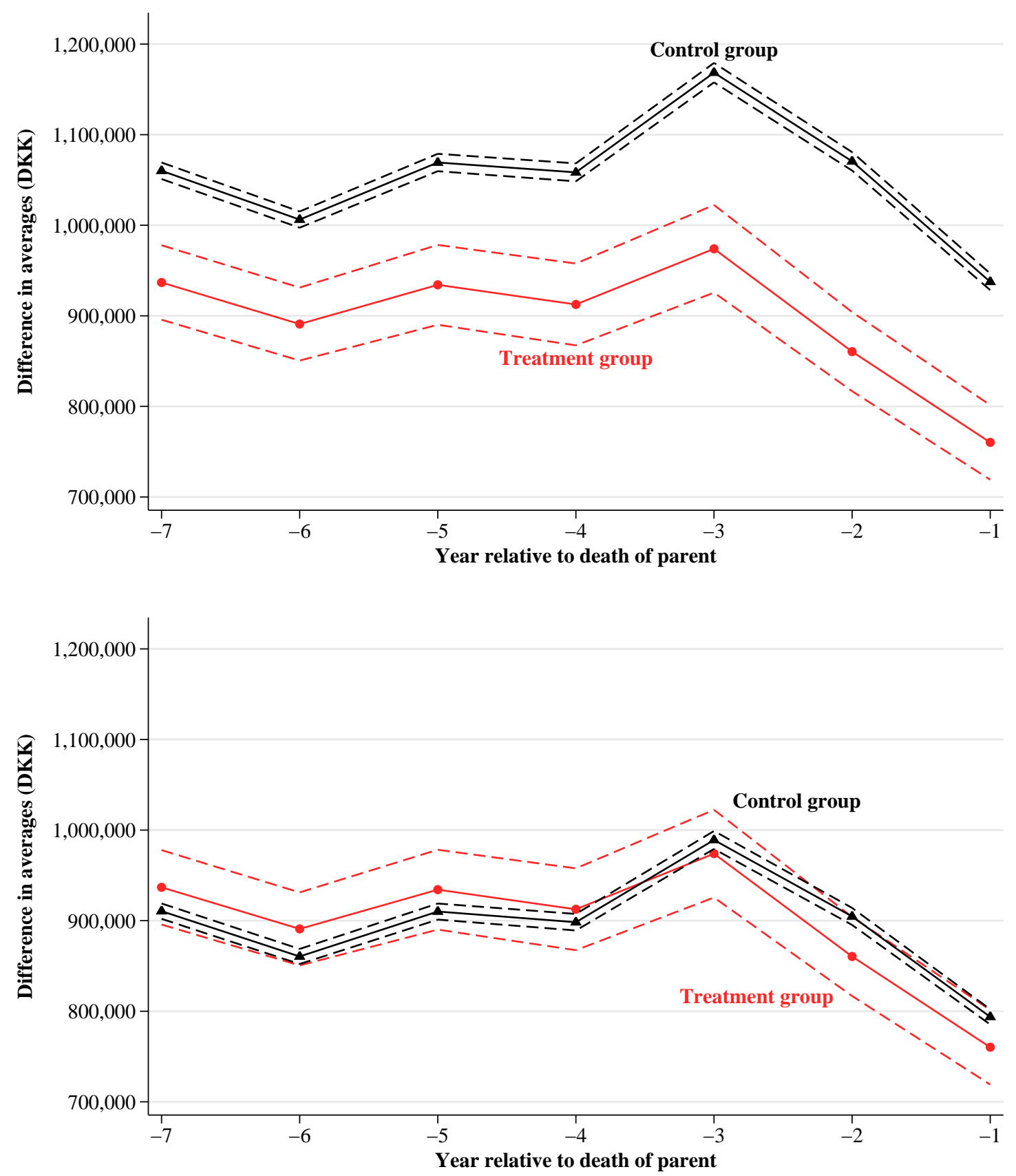

Figure A.4. Wealth of Parents Unweighted (top panel) and Weighted (bottom panel)

Note: The two figures display average wealth of T-group parents and C-group parents. The top panel is unweighted averages, while the bottom panel shows the result when reweighting the control group as explained in the text. All amounts in 2010 DKK. $\$ 1=$ DKK 5.6. Distributions censored at $1^{\text {st }}$ and $99^{\text {th }}$ percentiles. 


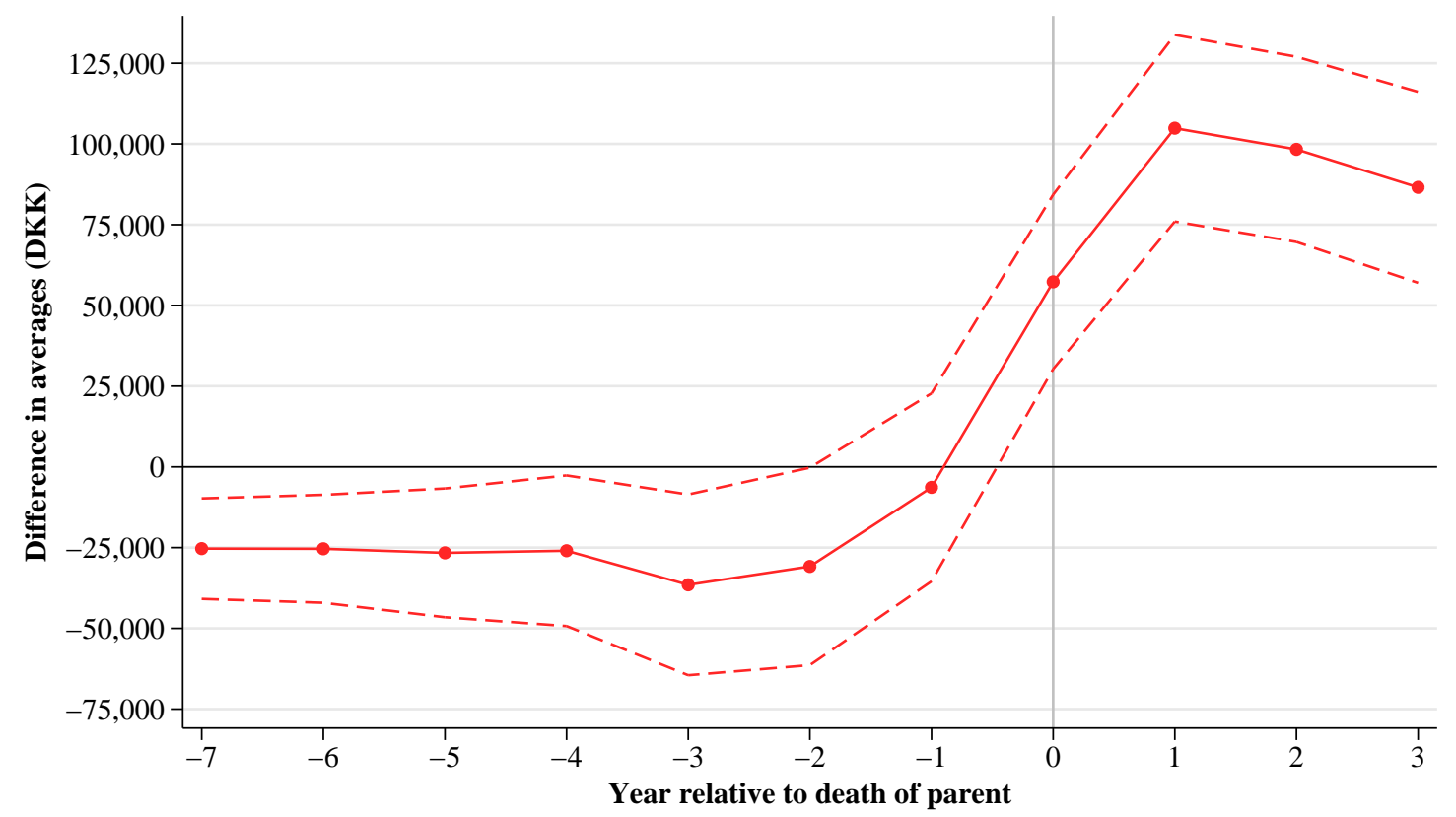

Figure A.5. Difference in Average Wealth of Treatment Group Children and Control Group Children (unweighted)

Note: The graph displays the unweighted average wealth of the treatment group relative to the control group. The graph may be compared to Figure 1, where the control group is reweighted as explained in the text. All amounts in 2010 DKK. $\$ 1=$ DKK 5.6. Distributions censored at $1^{\text {st }}$ and $99^{\text {th }}$ percentiles. 


\section{B Longer Term Effects of Bequests}

In the main text, we look at the cohorts who are 45-50 years old in 2010, where the parent dies in the treatment group, but not in the control group. We can only study the effect three years out and, by construction, over time parents in the control group are beginning to die as well. Below, we reconstruct Figures 1-3 in the paper for another sample. We follow the same cohorts but analyze instead the consequences of parental death in 2007, when children are 42-47 years old, and compare the individuals to a control group, where the parent is alive in 2013. This gives 4,926 individuals in the treatment group and 136,309 individuals in the control group. The advantage of this comparison is that we can study a longer term effect. The disadvantage is that the difference in the timing of parental deaths in the treatment and control groups is now at least seven years, whereas previously we allowed parents in the control group to die the year after, implying that the groups are possibly less similar now.

Figure B.1 shows that the short run impact on average wealth is DKK 125,000, which is the same as in Figure 1. Six years after death of the parent the effect is slightly above DKK 75,000, which is more than 60 percent of the effect on impact.

The effect on the variance of the wealth distribution is displayed in Figure B.2. Bequests increase the variance by close to 40 percent, which is a little larger than in Figure 2, and the effect is still 35 percent six years after.

The top $1 \%$ wealth shares of the treatment group and the control group are displayed in Figure B.3. The graphs are more noisy than those in Figure 3. However, it is still clear that the wealth share decreases relative to the control group after death of the parent. The difference between the two curves is approximately 20 percentage points prior to death of the parent and 10 percentage points after death of the parent, implying that the top $1 \%$ wealth share of the treatment group declines by around 10 percentage points, which is slightly higher than the effects obtained when studying death of parents in 2010. Finally, note that the curves are completely parallel after death

of the parent. Thus, the effect seems more or less constant over the six year period after receiving bequest. 


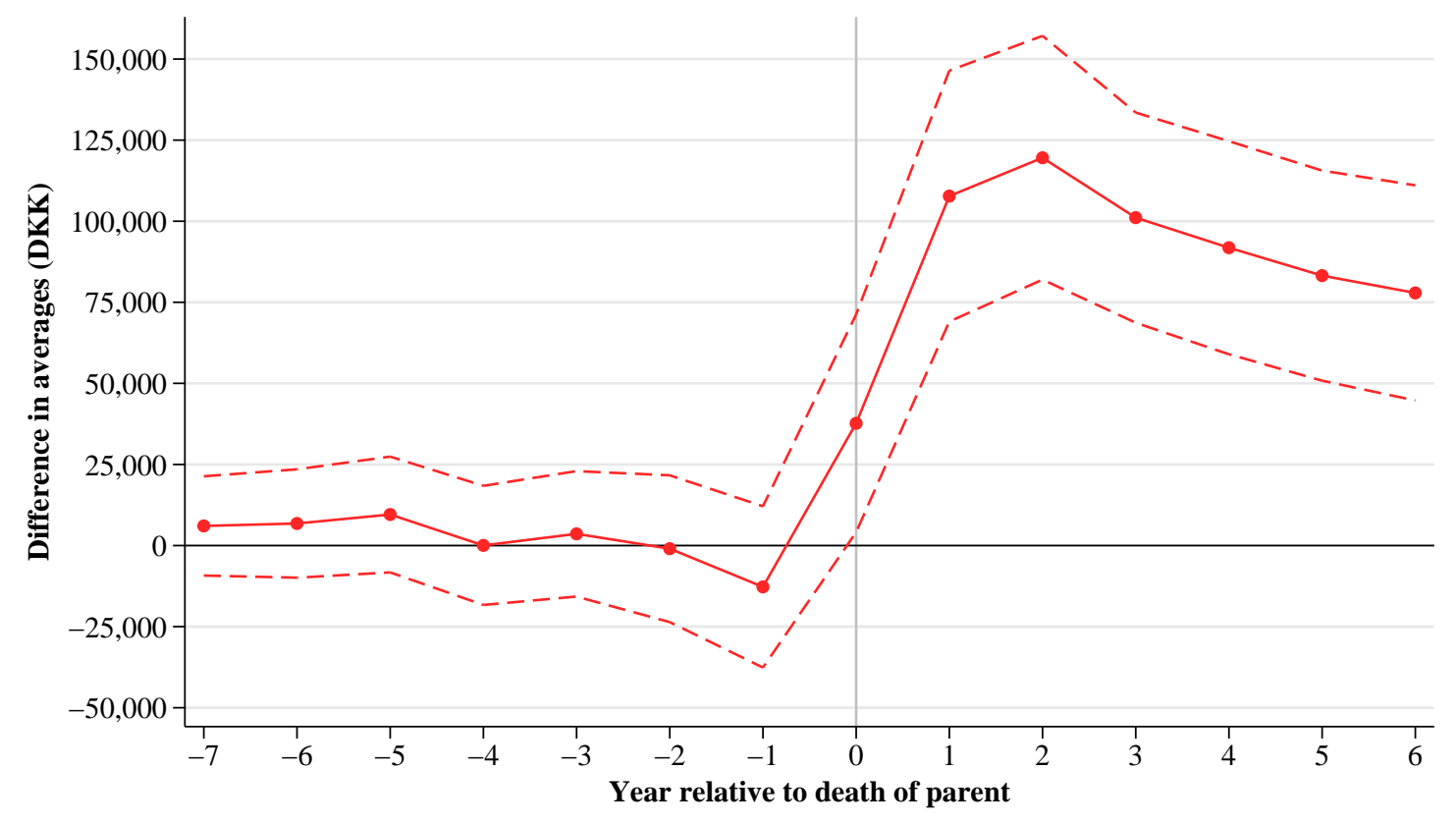

Figure B.1. Effect of Death of the Parent on Wealth of Children (parental death in 2007)

Note: The graph shows the difference in the average wealth of children of treatment group and control group with the control group reweighted to match, for each child cohort, the percentile distribution of parental wealth in the treatment group. Percentile ranks of parents are calculated within each child cohort based on average wealth in the seven years before death. Parental wealth is the sum of wealth of the living biological parents in each year. Amounts in 2010 DKK, $\$ 1=$ DKK5.6. Distributions censored at $1^{\text {st }}$ and $99^{\text {th }}$ percentiles. Dashed lines illustrate 95 percent confidence intervals based on standard errors clustered by parents (who may have more than one child). 


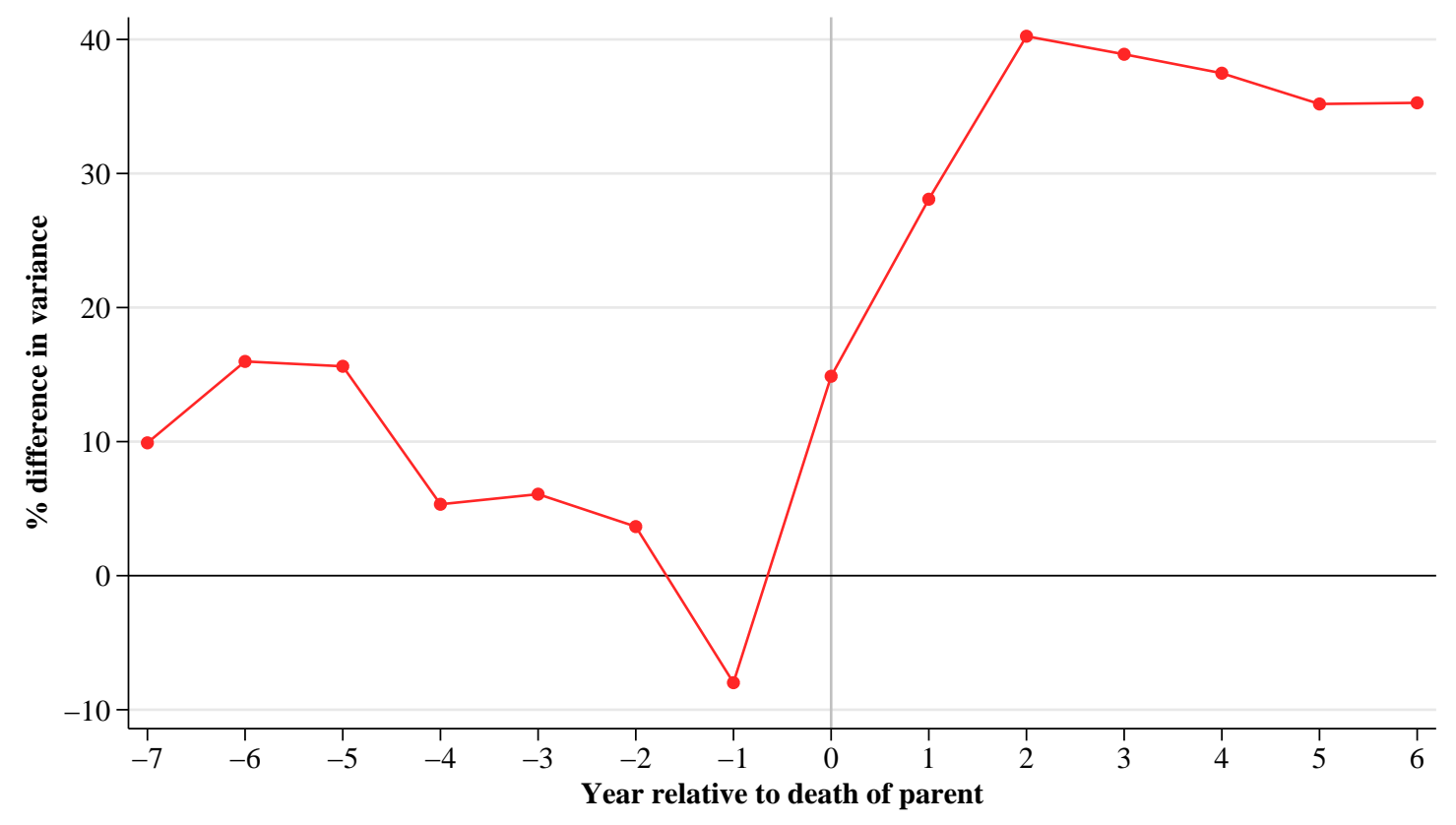

Figure B.2. Effects of Bequests on the Variance of Wealth (parental death in 2007)

Note: The graph shows the percentage difference in variance of treatment group relative to control group. The wealth distributions of the two groups are censored at the $1^{\text {st }}$ and $99^{\text {th }}$ percentiles. The control group is weighted as described in Figure B.1.

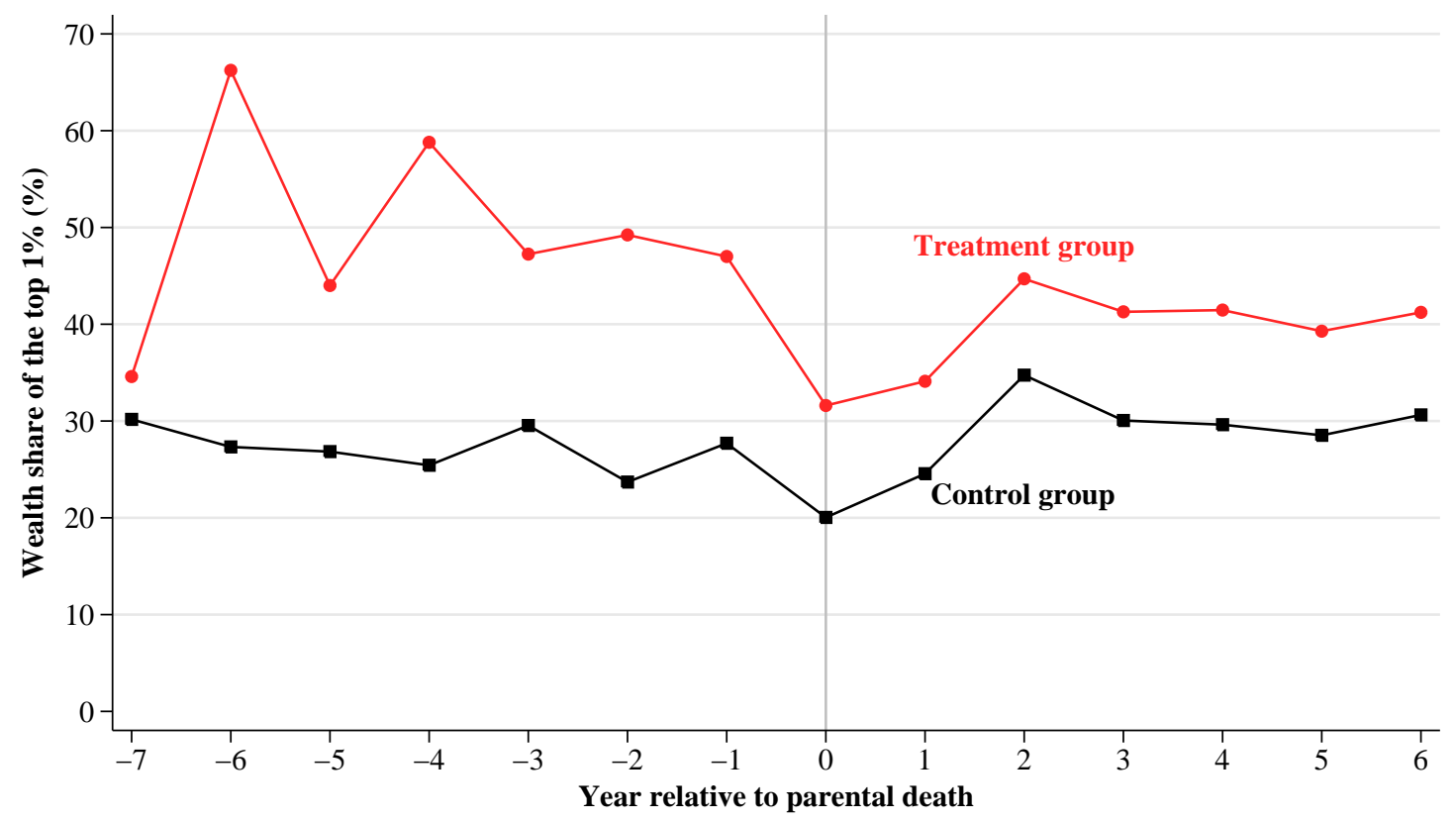

Figure B.3. Effect of Bequests on Top 1\% Share of Wealth (parental death in 2007)

Note: The graph shows the top $1 \%$ share in the treatment and control groups. The control group is weighted as described in Figure B.1. 